\title{
Guaranteed Cost Stabilization of a Class of Discrete Time Varying Systems
}

\author{
José Ernesto de Araujo Filho, Karl Heinz Kienitz, Member, IEEE
}

\begin{abstract}
A method to design stabilizing controllers for a class of discrete time varying systems with bounded time variance is presented in this contribution. It uses the guaranteed cost concept to assess the system's performance and the direct method of Lyapunov for stability considerations. Thus it resorts to techniques already known for uncertain systems. The controller determined using this method is given in terms of the solution to one of two modified Riccati equations.
\end{abstract}

\section{INTRODUCTION}

$\mathrm{T}$ HE guaranteed cost control (GCC) concept was introduced by Chang and Peng (1972) [3] in the context of uncertain systems. Uncertain systems are systems whose parameter variations, although unknown, lie within known bounds. The guaranteed cost control concept naturally relates to stability considerations via the direct method of Lyapunov (Chang and Peng, 1972). Initially it was discussed only for continuous time problems with finite time horizon. Its use for discrete time problems with finite time horizon was reported by Konstantinov et alii (1981) [10], and for discrete time problems with infinite time horizon by Kienitz (1990) [7] and [8]. A guaranteed cost control law is given in terms of a positive definite Lyapunov matrix calculated such that the system's stability is guaranteed via a negative Lyapunov difference [5] and [6]. The Lyapunov matrix itself allows for the determination of an upper bound on a designer chosen quadratic performance index (cost). This bound is denominated a guaranteed cost.

As system optimality loses its usefulness in the presence of parameter uncertainty, the guaranteed cost approach offers a substitute to system optimality. Since system optimality with respect to quadratic performance indices in infinite time horizon problems also loses its usefulness in the presence of time variance in general, even if the form of the time variation is known, the guaranteed cost approach is now used for discrete time varying systems.

J.E. Araujo Filho is with the Department of Control, Instituto Tecnológico de Aeronáutica (ITA/CTA), São José dos Campos - SP, 12.228 - 900, Brazil, e-mail: ernesto@ita.cta.br

K.H. Kienitz is with the Department of Control, Instituto Tecnológico de Aeronáutica (ITA/CTA), São José dos Campos - SP, 12.228 - 900, Brazil, e-mail: kienitz@ita.cta.br
In this contribution only the special class of linear discrete time varying systems described in section 2 is considered.

\section{PROBLEM STATEMENT}

Consider the time varying system in [4] and [9]:

$\mathbf{x}(\mathrm{k}+1)=[\mathrm{A}+\Delta \mathrm{A}(\mathrm{k})] \mathbf{x}(\mathrm{k})+[\mathrm{B}+\Delta \mathrm{B}(\mathrm{k})] \mathbf{u}(\mathrm{k})$

$\mathbf{x}(0)=\mathbf{x}_{0}$

where:

$\mathbf{x}(\mathrm{k}) \in \mathbf{R}^{\mathrm{n}}$ is the state vector;

$\mathbf{u}(\mathrm{k}) \in \mathbf{R}^{\mathrm{m}}$ is the control vector;

$\mathbf{x}_{0}$ is the initial condition;

$\mathrm{A} \in \mathbf{R}^{\mathrm{n} \times \mathrm{n}}, \mathrm{B} \in \mathbf{R}^{\mathrm{n} \times \mathrm{m}}$;

$\Delta \mathrm{A}(\mathrm{k})=\mathrm{D}_{1} \mathrm{~F}(\mathrm{k}) \mathrm{E}_{1}, \mathrm{D}_{1} \in \mathrm{R}^{\mathrm{nxp}}, \mathrm{E}_{1} \in \mathrm{R}^{\mathrm{pxn}} ;$

$\Delta \mathrm{B}(\mathrm{k})=\mathrm{D}_{2} \mathrm{~F}(\mathrm{k}) \mathrm{E}_{2} \mathrm{D}_{2} \in \mathrm{R}^{\mathrm{nxp}}, \mathrm{E}_{2} \in \mathrm{R}^{\mathrm{pxm}}$, and

$\xi^{\mathrm{T}} \mathrm{F}(\mathrm{k})^{\mathrm{T}} \mathrm{F}(\mathrm{k}) \xi \leq \xi^{\mathrm{T}} \xi, \forall \xi \in \mathbf{R}^{\mathrm{p}}$.

A quadratic performance index is given to assess the performance of the controlled system:

$$
\mathrm{J}(\mathrm{k})=\sum_{\mathrm{k}=0}^{\infty}\left[\mathbf{x}^{\mathrm{T}} \mathrm{Qx}\right]
$$

where $\mathrm{Q}>0$ is symmetric.

The following are sought:

- a stabilizing time varying state feedback controller $\mathbf{u}(\mathrm{k})=-\mathrm{K}(\mathrm{k}) \mathbf{x}(\mathrm{k})$ for system (1).

- an upper bound on (2) for system (1) subject to the stabilizing controller.

\section{PROBLEM SOLUTION}

The problem solution is presented in the form of two theorems. Depending on the nature of the time variance of system (1), one or the other theorem may be applicable. In particular two distinct cases with respect to the structure of the time variance are considered: matched time variance (the range spaces of $\Delta \mathrm{A}$ and $\Delta \mathrm{B}$ lie in the range space of $\mathrm{B}$, i.e., $\mathrm{D}$ $=\mathrm{BX}$, for some suitable $\mathrm{X}$ ), and the mismatched case (the range spaces of $\Delta \mathrm{A}$ and $\Delta \mathrm{B}$ do not lie entirely in the range space of B) [1]. 
Consider this controller form:

$$
\mathbf{u}(\mathrm{k})=-\mathrm{K}(\mathrm{k}) \mathbf{x}(\mathrm{k})
$$

where:

$$
\mathrm{K}(\mathrm{k})=\left[\mathrm{B}(\mathrm{k})^{\mathrm{T}} \mathrm{P} \mathrm{B}(\mathrm{k})\right]^{-1} \mathrm{~B}^{\mathrm{T}}(\mathrm{k}) \operatorname{PA}(\mathrm{k}),
$$

and the following notation:

$$
\left.\begin{array}{l}
H=I-B\left(B^{T} P B\right)^{-1} B^{T} P \\
\tilde{D}=H D \\
\gamma_{1}=\lambda_{\text {max }}\left(D_{1}^{\mathrm{T}} H^{\mathrm{T}} P H D_{1}\right)
\end{array}\right\}
$$

\section{Theorem 1:}

Consider a linear discrete time varying system (1) with known time variance. Further suppose that the columns of $D_{1}$ and $D_{2}$ are linear combinations of the columns of $\mathrm{B}$. If the pair $(\mathrm{A}, \mathrm{B})$ is controllable and $[\mathrm{B}+\Delta \mathrm{B}(\mathrm{k})]$ has full column rank, a stabilizing controller for the system is given in (3) where $\mathrm{P}$ is the positive definite symmetric solution of the Riccati equation:

$$
\mathrm{A}^{\mathrm{T}} \mathrm{PHA}-\mathrm{P}+\mathrm{Q}=0 .
$$

Furthermore the controlled system is optimal with respect to (2) and the value of the cost is given by $\mathbf{J}=\mathbf{x}_{0}^{\mathrm{T}} \mathrm{P} \mathbf{x}_{0}$, where $\mathbf{x}_{0}$ is the initial condition of the system.

Proof: see the Appendix

\section{Theorem 2:}

Consider a linear discrete time varying system (1) with known time variance. Further, suppose that only the columns of $D_{2}$ are linear combinations of the columns of $\mathrm{B}$. If the pair $(\mathrm{A}, \mathrm{B})$ is controllable and $[\mathrm{B}+\Delta \mathrm{B}(\mathrm{k})]$ has full column rank, a stabilizing controller for the system is given in (3) where $\mathrm{P}$ is the positive definite symmetric solution of the Riccati equation:

$$
(1+\varepsilon) \mathrm{A}^{\mathrm{T}} \mathrm{PHA}+\left(\gamma_{1}+\frac{\gamma_{1}}{\varepsilon}\right) \mathrm{E}_{1}^{\mathrm{T}} \mathrm{E}_{1}-\mathrm{P}+\mathrm{Q}=0
$$

and $\mathrm{P}$ satisfies $\mathrm{P}=\left(\mathrm{P}_{1}^{-1}+\tilde{\mathrm{D}} \tilde{\mathrm{D}}^{\mathrm{T}}\right)^{-1}$, for some positive definite matrix $P_{1}$ and some $\varepsilon>0$.

Furthermore the value of the cost is given by $\mathrm{J}=\mathbf{x}_{0}^{\mathrm{T}} \mathrm{P} \mathbf{x}_{0}$, where $\mathbf{x}_{0}$ is the initial condition of the system.

Proof: see the Appendix

\section{ILLUSTRATIVE EXAMPLE:}

For the purpose of illustration consider the following system [2], [8] and [9]:

$$
\begin{gathered}
\mathbf{x}(\mathrm{k}+1)=\left[\begin{array}{ccc}
0.48[1+\mathrm{f}(\mathrm{k})] & -7+3 \mathrm{~g}(\mathrm{k}) & 0 \\
0,051 & 0.74 & 0 \\
0 & -1 & 1
\end{array}\right] \mathbf{x}(\mathrm{k})+\cdots \\
\cdots+\left[\begin{array}{c}
7.3 \\
0.272 \\
0
\end{array}\right](1+0.2 \mathrm{~h}(\mathrm{k})) \mathrm{u}(\mathrm{k})
\end{gathered}
$$

where $|\mathrm{f}(\mathrm{k})| \leq 1|\mathrm{~g}(\mathrm{k})| \leq 1 \mathrm{e}|\mathrm{h}(\mathrm{k})| \leq 1$ are known parameter variations in time.

$$
\begin{aligned}
\text { Thus } & \mathrm{A}=\left[\begin{array}{ccc}
0.48 & -7 & 0 \\
0.051 & 0.74 & 0 \\
0 & -1 & 1
\end{array}\right] ; \mathrm{B}=\left[\begin{array}{c}
7.3 \\
0.272 \\
0
\end{array}\right], \\
& \Delta \mathrm{A}=\left[\begin{array}{ccc}
0.48 \mathrm{f}(\mathrm{k}) & 3 \mathrm{~g}(\mathrm{k}) & 0 \\
0 & 0 & 0 \\
0 & 0 & 0
\end{array}\right]= \\
= & {\left[\begin{array}{ccc}
1 & 1 & 1.46 \\
0 & 0 & 0.054 \\
0 & 0 & 0
\end{array}\right]\left[\begin{array}{cccc}
\mathrm{f}(\mathrm{k}) & 0 & 0 \\
0 & \mathrm{~g}(\mathrm{k}) & 0 \\
0 & 0 & \mathrm{~h}(\mathrm{k})
\end{array}\right]\left[\begin{array}{ccc}
0.48 & 0 & 0 \\
0 & 3 & 0 \\
0 & 0 & 0
\end{array}\right] }
\end{aligned}
$$

and

$$
\Delta \mathrm{B}=\left[\begin{array}{c}
1.46 \\
0.054 \\
0
\end{array}\right] \mathrm{h}(\mathrm{k})=\left[\begin{array}{ccc}
1 & 1 & 1.46 \\
0 & 0 & 0.054 \\
0 & 0 & 0
\end{array}\right]\left[\begin{array}{ccc}
\mathrm{f}(\mathrm{k}) & 0 & 0 \\
0 & \mathrm{~g}(\mathrm{k}) & 0 \\
0 & 0 & \mathrm{~h}(\mathrm{k})
\end{array}\right]\left[\begin{array}{l}
0 \\
0 \\
1
\end{array}\right]
$$

and consider the quadratic performance index (2) so that:

$$
\mathrm{Q}=\left[\begin{array}{ccc}
0.06 & 0 & 0 \\
0 & 1 & 0 \\
0 & 0 & 0.1
\end{array}\right]
$$

This system can be stabilized using theorem 2. The positive definite symmetric solution to (6) with $\mathrm{Q}$ as given above is:

$$
\mathrm{P}=\left[\begin{array}{ccc}
0.1313 & 1.9038 & -0.5433 \\
1.9038 & 89.8115 & -30.2472 \\
-0.5433 & -30.2472 & 13.9262
\end{array}\right]
$$

A stabilizing controller is found from (3):

$$
\begin{aligned}
& \mathrm{K}(\mathrm{k})=(1+0.2 \overline{\mathrm{h}}(\mathrm{k}))^{-1} \ldots \\
& \quad \ldots[0.1256+0.0334 \overline{\mathrm{f}}(\mathrm{k}) \quad 1.4254+0.2088 \overline{\mathrm{g}}(\mathrm{k}) \quad-0.5751]
\end{aligned}
$$

The solution to the modified Riccati equation was found using an iterative algorithm similar to that proposed by Strejc 
(1981) [11] for Riccati equations.

The system was simulated using the parameter functions depicted in Figure 1.

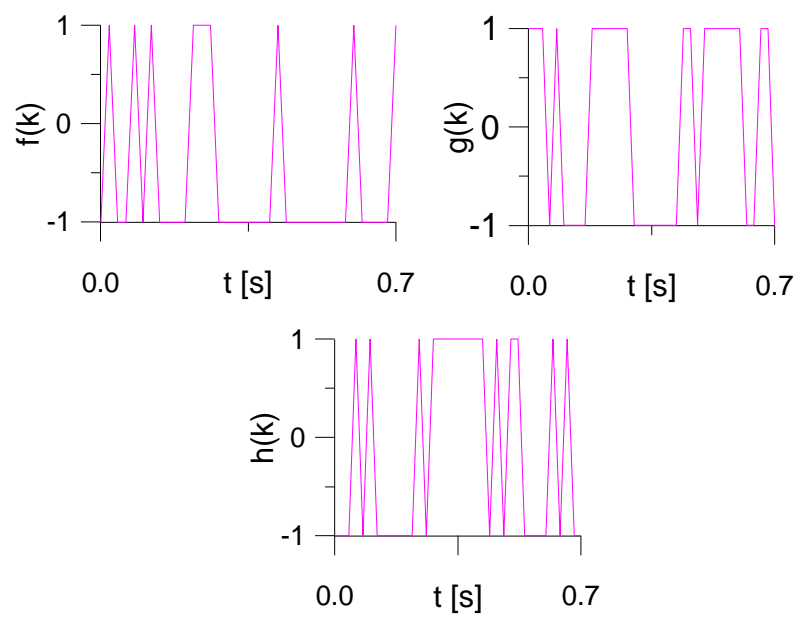

Figure 1: Parameters for system (7)

The system response is shown in Figure 2, together with the response of the system subject to the optimal controller designed for the nominal system, i.e. the system with $\mathrm{h}(\mathrm{k})=\mathrm{g}(\mathrm{k})=\mathrm{f}(\mathrm{k}) \equiv 0$.
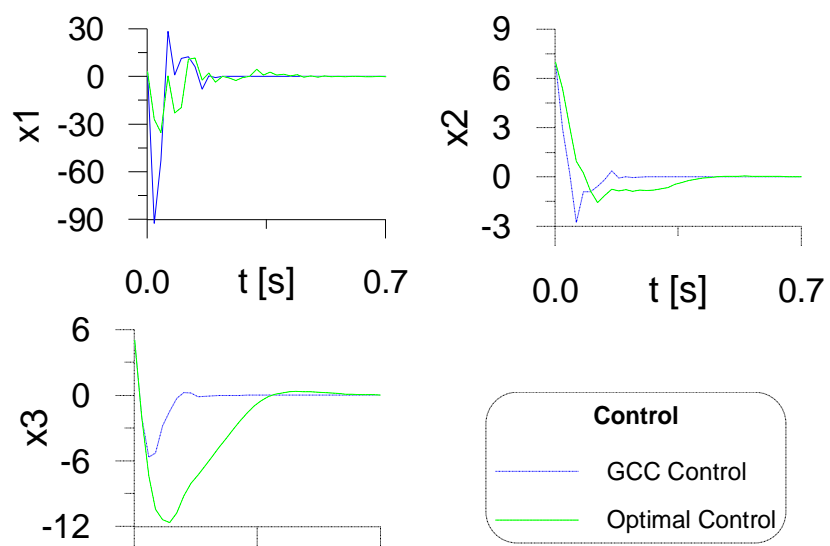

\section{$\begin{array}{lll}0.0 & \mathrm{t}[\mathrm{s}] & 0.7\end{array}$ \\ Figure 2: System response V. CONCLUSION}

In this contribution it was shown how the guaranteed cost results derived for uncertain discrete systems can be applied to the design of stabilizing controllers for time varying discrete systems.

\section{REFERENCES}

[1] Barmish, B.R., Corless, M., Leitmann, G. "A New Class of Stabilizing Controllers for Uncertain Dynamical Systems" SIAM J. Control Optim., v. 21, n. 2, p. 246-255, Mar. 1983.
[2] Chai, W., Loh, K. N., Poo, A. N. "Stabilizing Uncertain Discrete-Time Systems by Observer-based Control" Int. J. Systems Sci, v. 25, n. 1, p. 47-64, Dec. 1991.

[3] Chang, S.S.L., Peng, T.K.C. "Adaptative Guaranteed Cost Control of Systems with Uncertain Parameters" IEEE Transaction on Automatic Control, v. 17, n. 4, p. 474-483, Aug. 1972.

[4] De Souza, C. E., Fu, M., Xie, L. "Hळ Analysis and Synthesis of Discrete-Time Systems with TimeVarying Uncertainty" IEEE Transactions on Automatic Control, v. 38, n. 3, p. 459-461, Mar. 1993.

[5] Kalman, R.E. Bertram, J.E. "Control System Analysis and Design Via the 'Second Method' of Lyapunov Part I: Continous-Time Systems" Journal of Basic Engineering, v. 82, p. 371-393, June 1960.

[6] . "Control System Analysis and Design Via the 'Second Method' of Lyapunov - Part II: DiscreteTime Systems" Journal of Basic Engineering, v. 82, p. 394-400, June 1960.

[7] Kienitz, K. H. (Ph.D. Dissertation) "Stabilization of Uncertain Discrete Systems". Zürich: ETH - Swiss Federal Institute of Technology, 1990. 127 p.

[8] _ Guaranteed Cost Control Approach to the Stabilization of Uncertain Linear Discrete-Time Systems" International Journal of Systems and Science, v. 21, n. 4, p. 643-652, Jan. 1990.

[9]__ _ _ Guaranteed Cost Stabilization for a Class of Uncertain Discrete-Time Systems" (preprint).

[10] Konstantinov, M.M. et al. "Synthesis of Discrete Systems with Guaranteed Cost" Problems of Engineering Cybernetics, v. 11, p. 34-40, 1981.

[11] Strejc, V. State Space Theory of Discrete Linear Control. Praga: John Wiley \& Sons, 1981. 426 p.

\section{APPENDIX}

\section{Proof of theorem 1:}

Lyapunov theory will guarantee the stability of the controlled system (1) if:

$$
\Delta \mathrm{V}(\mathbf{x})=\mathbf{x}(\mathrm{k}+1)^{\mathrm{T}} \mathrm{P} \mathbf{x}(\mathrm{k}+1)-\mathbf{x}(\mathrm{k})^{\mathrm{T}} \mathrm{P} \mathbf{x}(\mathrm{k})<0
$$

Using the control law (3):

$$
\begin{aligned}
\Delta \mathbf{V}(\mathbf{x})= & \left\{\left\{\begin{array}{l}
{[\mathrm{A}+\Delta \mathrm{A}(\mathrm{k})]-\cdots} \\
\cdots-[\mathrm{B}+\Delta \mathrm{B}(\mathrm{k})] \mathrm{K}(\mathrm{k})
\end{array}\right\} \mathbf{x}(\mathrm{k})\right\}^{\mathrm{T}}\left\{\mathrm{P}\left\{\left\{\begin{array}{l}
{[\mathrm{A}+\Delta \mathrm{A}(\mathrm{k})]-\cdots} \\
\cdots-[\mathrm{B}+\Delta \mathrm{B}(\mathrm{k})] \mathrm{K}(\mathrm{k})
\end{array}\right\} \mathbf{X}(\mathrm{k})\right\}-\cdots\right. \\
& \cdots-\mathbf{x}(\mathrm{k})^{\mathrm{T}} \mathrm{P} \mathbf{x}(\mathrm{k})<0
\end{aligned}
$$

This yields:

$\Delta \mathrm{V}(\mathbf{x})=\mathbf{x}^{\mathrm{T}}\left\{\begin{array}{l}(\mathrm{A}+\Delta \mathrm{A})^{\mathrm{T}} \mathrm{P}(\mathrm{A}+\Delta \mathrm{A})-\mathrm{P}-(\mathrm{A}+\Delta \mathrm{A})^{\mathrm{T}} \mathrm{P}(\mathrm{B}+\Delta \mathrm{B}) \cdots \\ \ldots\left[(\mathrm{B}+\Delta \mathrm{B})^{\mathrm{T}} \mathrm{P}(\mathrm{B}+\Delta \mathrm{B})\right]^{-1}(\mathrm{~B}+\Delta \mathrm{B})^{\mathrm{T}} \mathrm{P}(\mathrm{A}+\Delta \mathrm{A})\end{array}\right\} \mathbf{x}<0$ 
(13)

Because the time variance of system is considered matched assumption the third term of the inequality above is equal to:

$$
\begin{aligned}
& (\mathrm{A}+\Delta \mathrm{A})^{\mathrm{T}} \mathrm{P}\left(\mathrm{B}+\mathrm{B} \alpha \mathrm{FE}_{2}\right)\left[\left(\mathrm{B}+\mathrm{B} \alpha \mathrm{FE}_{2}\right)^{\mathrm{T}} \mathrm{P}\left(\mathrm{B}+\mathrm{B} \alpha \mathrm{FE}_{2}\right)\right]^{-1} \ldots \\
& \ldots\left(\mathrm{B}+\mathrm{B} \alpha \mathrm{FE}_{2}\right)^{\mathrm{T}} \mathrm{P}(\mathrm{A}+\Delta \mathrm{A})
\end{aligned}
$$

which can be rewritten as

$$
(\mathrm{A}+\Delta \mathrm{A})^{\mathrm{T}} \mathrm{P} \mathrm{B}\left(\mathrm{B}^{\mathrm{T}} \mathrm{PB}\right)^{-1} \mathrm{~B}^{\mathrm{T}} \mathrm{P}(\mathrm{A}+\Delta \mathrm{A})
$$

Thus:

$$
\Delta V(\mathbf{x})=\mathbf{x}^{\mathrm{T}}\left\{(\mathrm{A}+\Delta \mathrm{A})^{\mathrm{T}} \mathrm{P}\left[\mathrm{I}-\mathrm{B}\left(\mathrm{B}^{\mathrm{T}} \mathrm{PB}\right)^{-1} \mathrm{~B}^{\mathrm{T}} \mathrm{P}\right](\mathrm{A}+\Delta \mathrm{A})-\mathrm{P}\right\} \mathbf{x}<0
$$

and using $\mathrm{H}$ from eq. (4) the following results:

$$
\Delta \mathrm{V}(\mathbf{x})=\mathbf{x}^{\mathrm{T}}\left(\mathrm{A}^{\mathrm{T}} \mathrm{PHA}+2 \mathrm{~A}^{\mathrm{T}} \mathrm{PH} \Delta \mathrm{A}+\Delta \mathrm{A}^{\mathrm{T}} \mathrm{PH} \Delta \mathrm{A}-\mathrm{P}\right) \mathbf{x}<0
$$

Using $\Delta \mathrm{A}=\mathrm{D}_{1} \mathrm{~F}(\mathrm{k}) \mathrm{E}_{1}$ the eq. (17) can be written as:

$$
\Delta \mathrm{V}(\mathbf{x})=\mathbf{x}^{\mathrm{T}}\left[\begin{array}{c}
\mathrm{A}^{\mathrm{T}} \mathrm{PHA}+2 \mathrm{~A}^{\mathrm{T}} \mathrm{PH}\left(\mathrm{D}_{1} \mathrm{FE}_{1}\right)+\ldots \\
\ldots+\left(\mathrm{D}_{1} \mathrm{FE}_{1}\right)^{\mathrm{T}} \mathrm{PH}\left(\mathrm{D}_{1} \mathrm{FE}_{1}\right)-\mathrm{P}
\end{array}\right] \mathbf{x}<0
$$

which yields to the Riccati equation given in the Theorem. The optimality of the controller is demonstrated starting from the general form of an optimal controller for a time varying system and substituting the expressions for $\Delta \mathrm{A}$ and $\Delta \mathrm{B}$ into it.

\section{Proof of theorem 2:}

Lyapunov theory will guarantee the stability of the controlled system (1) if:

$$
\Delta \mathrm{V}(\mathbf{x})=\mathbf{x}(\mathrm{k}+1)^{\mathrm{T}} \mathrm{P} \mathbf{x}(\mathrm{k}+1)-\mathbf{x}(\mathrm{k})^{\mathrm{T}} \mathrm{P} \mathbf{x}(\mathrm{k})<0
$$

Using the control law (3):

$$
\begin{aligned}
\Delta V(\mathbf{x})= & \left\{\left\{\begin{array}{l}
{[\mathrm{A}+\Delta \mathrm{A}(\mathrm{k})]-\cdots} \\
\cdots-[\mathrm{B}+\Delta \mathrm{B}(\mathrm{k})] \mathrm{K}(\mathrm{k})
\end{array}\right\} \mathbf{x}(\mathrm{k})\right\}^{\mathrm{T}}\left\{\mathrm{P}\left\{\left\{\begin{array}{l}
{[\mathrm{A}+\Delta \mathrm{A}(\mathrm{k})]-\cdots} \\
\cdots-[\mathrm{B}+\Delta \mathrm{B}(\mathrm{k})] \mathrm{K}(\mathrm{k})
\end{array}\right\} \mathrm{x}(\mathrm{k})\right\}-\cdots\right. \\
& \cdots-\mathbf{x}(\mathrm{k})^{\mathrm{T}} \mathrm{Px}(\mathrm{k})<0
\end{aligned}
$$

This yields:

$\Delta V(\mathbf{x})=\mathbf{x}^{\mathrm{T}}\left\{\begin{array}{l}(\mathrm{A}+\Delta \mathrm{A})^{\mathrm{T}} \mathrm{P}(\mathrm{A}+\Delta \mathrm{A})-\mathrm{P}-(\mathrm{A}+\Delta \mathrm{A})^{\mathrm{T}} \mathrm{P}(\mathrm{B}+\Delta \mathrm{B}) \cdots \\ \ldots\left[(\mathrm{B}+\Delta \mathrm{B})^{\mathrm{T}} \mathrm{P}(\mathrm{B}+\Delta \mathrm{B})\right]^{-1}(\mathrm{~B}+\Delta \mathrm{B})^{\mathrm{T}} \mathrm{P}(\mathrm{A}+\Delta \mathrm{A})\end{array}\right\} \mathbf{x}<0$

In this case the time variance in $\mathrm{B}$ is considered matched assumption and the time variance in $\mathrm{A}$ is considered unmatched assumption. Substituting them in the inequality above the resulting form is:

$\Delta \mathrm{V}(\mathbf{x})=\mathbf{x}^{\mathrm{T}}\left(\mathrm{A}^{\mathrm{T}} \mathrm{P} H \mathrm{~A}+2 \mathrm{~A}^{\mathrm{T}} \mathrm{PH} \Delta \mathrm{A}+\Delta \mathrm{A}^{\mathrm{T}} \mathrm{PH} \Delta \mathrm{A}-\mathrm{P}\right) \mathbf{x}<0$

Using the claims 1 and 2 presented in [8] the inequation above may be rewritten as:

$$
\Delta \mathrm{V}(\mathbf{x})=\mathbf{x}^{\mathrm{T}}\left[(1+\varepsilon) \mathrm{A}^{\mathrm{T}} \mathrm{H}^{\mathrm{T}} \mathrm{PHA}+\left(1+\frac{1}{\varepsilon}\right) \Delta \mathrm{A}^{\mathrm{T}} \mathrm{H}^{\mathrm{T}} \mathrm{PH} \Delta \mathrm{A}-\mathrm{P}\right] \mathbf{x}<0
$$

Using $\Delta \mathrm{A}=\mathrm{D}_{1} \mathrm{~F}(\mathrm{k}) \mathrm{E}_{1}$ this inequality is equivalent to:

$\Delta \mathrm{V}(\mathbf{x})=\mathbf{x}^{\mathrm{T}}\left[\begin{array}{c}(1+\varepsilon) \mathrm{A}^{\mathrm{T}} \mathrm{H}^{\mathrm{T}} \mathrm{P} \mathrm{HA}+\ldots \\ \ldots+\left(1+\frac{1}{\varepsilon}\right) \mathrm{E}_{1}^{\mathrm{T}} \mathrm{F}^{\mathrm{T}} \lambda_{\text {max }}\left(\mathrm{D}_{1}^{\mathrm{T}} \mathrm{H}^{\mathrm{T}} \mathrm{PHD}_{1}\right) \mathrm{FE}_{1}-\mathrm{P}\end{array}\right] \mathbf{x}<0$

Using the claim 3 presented in [9] thus one is:

$$
\Delta \mathrm{V}(\mathbf{x})=\mathbf{x}^{\mathrm{T}}\left[(1+\varepsilon) \mathrm{A}^{\mathrm{T}} \mathrm{PHA}+\left(\gamma_{1}+\frac{\gamma_{1}}{\varepsilon}\right) \mathrm{E}_{1}^{\mathrm{T}} \mathrm{E}_{1}-\mathrm{P}\right] \mathbf{x}<0
$$

which yields to the Riccati equation given in the Theorem. The demonstration of guaranteed cost is given in [8]. 